\title{
TONGUES UNTIED: POLYPHONIC IDENTITIES AND THE HISPANIC FAMILY
}

\author{
José Medina \\ Vanderbilt University
}

\section{Toward a Polyphonic View of Cultural Identity}

In this paper I will use the Bakhtinian notion of polyphony, of a choral dialogue of multiple and heterogeneous voices, to elaborate a pluralistic account of cultural identity in general and of Hispanic identity in particular. I will complicate and further pluralize the Bakhtinian notion by talking about the overlapping and criss-crossing dialogues of heterogeneous voices that go into the formation of cultural identities. My pluralistic view emphasizes that cultural identity is bound up with differences and opposes those homogeneous models that try to impose a unique articulation of collective identity on the members of a group. Although I will not explicitly discuss the complex relations between cultural identity and racial and ethnic identity, ${ }^{2}$ my pluralistic view underscores that racial and ethnic elements are crucial components of cultural identity and of its heterogeneous nature; and I oppose those contemporary views that talk about "post-ethnic" and "post-racial" identities, trying to purify individual and collective identities of racial and ethnic meanings. ${ }^{3}$

Cultural differences are everywhere. There is no way around this omnipresent cultural heterogeneity in the 21 st century. It has 
become clear that the globalized world of today is a pluri-verse, rather than a uni-verse, and that multiculturalism is not simply the exotic peculiarity of some post-colonial societies, but the inescapable predicament of the contemporary world community. But even multicultural views of today's world and its communities are often not pluralistic enough because they frequently assume a homogeneous view of the participating cultural identities, as if each of them had a unique voice and could make only one unique contribution to the multicultural dialogue. It will be my contention that not only multicultural societies are polyphonic, but each cultural group (no matter how homogeneous it may appear to be) contains a plurality of voices. Cultures speak in many voices. ${ }^{4}$ They are heterogeneous through and through. Differences and heterogeneity go all the way down to the very core of a cultural identity. So we need an account that can make sense of identity through differences, not in spite of them.

Through the notion of polyphony I will try to articulate a pluralistic perspective that can shed light on how cultural identities are formed, sustained, and transformed, as well as on how they interact with one another in cross-cultural dialogues. A philosophical elucidation of polyphonic dialogues within and across cultures is now needed more than ever. For cultural differences have come under suspicion and the appreciation of their positive significance has become a difficult challenge. The radical pluralism I articulate and defend in this paper highlights the positive contributions of cultural diversity and the dangers of trying to repress it, tame it, constrain it, or make it fit in fixed molds and restricted spaces. As it will become clear in the last section when I apply my pluralistic approach to situated Hispanic identities in particular cultural contexts, the goal of my polyphonic view is to facilitate playful and diverse forms of identification and to open up sites for disidentification, ${ }^{5}$ calling attention to alternative cultural spaces in which different (non-conforming) identities-distanced from mainstream culture - can flourish.

In the next section I will articulate my pluralistic view by elaborating central insights that I draw from Wittgenstein's philosophy of language and philosophy of culture. I will further develop my polyphonic pluralism in the third and final section by elucidating the linguistic and cultural practices of Hispanics in particularly challenging contexts: Chicanos living by the Mexico- 
USA border, en la frontera; and marginalized groups living in urban ghettos in Mexico City.

\section{Wittgenstein and the Hispanic family}

In this section I try to determine what the contemporary philosophical debate about Hispanic identity can learn from the historical, practical, and normative contextualism that informs Wittgenstein's later philosophy. I argue that from Wittgenstein's notion of family resemblance we can derive a non-essentialist and pluralistic view of cultural identity as something that is historically situated, action-based, and value-laden. So the three crucial ingredients of my Wittgensteinian familial view of cultural identity are historicity, agency, and normativity. On my view, cultural identity is produced and maintained by historical practices; secondly, it is crucially dependent on the agency of its members and also on the agency of those with whom they interact; and finally, a cultural identity has a normative dimension, that is, membership in the cultural group is informed by normative attitudes (attitudes that may be quite heterogeneous and often remain implicit). I develop my Wittgensteinian familial view of Hispanic identity in two stages. In the first stage I offer a critical examination of Jorge Gracia's familial account. There I argue that Gracia's account is not Wittgensteinian enough and I criticize its metaphysical presuppositions from a Wittgensteinian perspective. In the second and more positive stage of my argument I develop my own polyphonic interpretation of the notion of family resemblance and apply it to Hispanic identity.

\section{2a. Gracia's Familial View: History without Agency and Normativity.}

In Hispanic/Latino Identity Gracia (2000) argues that the collective identity of Hispanics should be understood as the identity of a historical family formed by "a unique web of changing historical relations." (p. 49) On this familial-historical view, the unity of Hispanics is not a unity of commonality, but a unity of community, "a historical unity founded on relations." (p. 50) According to Gracia, the origin of the complex history that unites "our Hispanic family" is "the encounter" of Iberia and America in 1492. Gracia argues that the term "Hispanic" is the only appropriate name for our historical family because it 
is the only label that can bring together all those lberians and Americans who have come to share a cultural identity as a result of historical events. Rather than discussing the validity of these specific contentious claims, I want to discuss instead the general strengths and weaknesses of Gracia's familial view.

The main strength of Gracia's familial-historical view is its capacity to account for change and diversity as fundamental aspects of Hispanic identity. On Gracia's view the cultural identity of a group is neither static nor homogeneous. On the one hand, Gracia's diachronic view depicts Hispanic identity as something dynamic that is always in the making and can never be fixed once and for all. This picture brings to the fore the contingencies of the past that have contributed to the formation of our Hispanic identity; and it underscores that the future of our Hispanic family remains open: "The future is always open and can be different. We are not trapped in our identity." (p. 190) On the other hand, Gracia's familial-historical view emphasizes the heterogeneous character of Hispanic identity: Hispanics share only "family resemblances" and their identity "is bound up with difference." (p. 33) Gracia's familial analysis shows that the homogeneity of group identity is a myth, for families are not homogeneous wholes composed of pure elements: "They include contradictory elements and involve mixing. Indeed, contradiction and mixing seems to be of the essence, for a living unity is impossible without contradiction and heterogeneity." (p.50) This is particularly true of our Hispanic family that has been constituted through mixing or mestizaje at all levels.

Despite its unquestionable virtues, Gracia's familial-historical view has also some weaknesses. A critical look at the externalist and realist view of history that animates Gracia's account of Hispanic identity can help to uncover some of its problematic assumptions. In the first place, it is highly questionable that what gives unity to our Hispanic family is history per se and not the appropriation of that history in and through our practices. However, Gracia's externalist view of history forces him to this implausible conclusion: "What ties [a group of people] together, and separates them from others, is history and the particular events of that history rather than the consciousness of that history." ( $p$. 49) But it is far from clear that having a distinctive history is a sufficient condition for collective identity. This externalist claim 
belies the fundamental practical dimension of cultural identity, which involves agency and is not something that simply happens to us as a result of history. The explicit recognition of this practical aspect of Hispanic identity is essential for the self-empowerment of the group.

In the second place, Gracia's familial-historical view shares with essentialist views the ambition of finding a metaphysical grounding for Hispanic identity that is independent of political viewpoints. However, it seems implausible that history can provide such value-free grounding. Gracia insists that our philosophical justifications of claims about Hispanic identity "should not be based on politics, but on historical fact." (p. 67) But unless a strong fact/value distinction is invoked, it is not at all clear that history and politics can be kept separate. Gracia seems to be reacting against accounts that have explicitly tied Hispanic/Latino identity to particular social and political agendas such as liberation. ${ }^{6}$ Although Gracia acknowledges the crucial importance of the project of liberation in Latin America, he does not think that liberation should be considered as a constitutive element of Hispanicity, for the idea of liberation has not played the same key role everywhere in the Hispanic world and it is not clear that it will in the future. This is indeed true, but it should not be a problem for a philosophical account of Hispanic identity that is developed for our here and now rather than for all times and all places. And this brings us to the unWittgenstenian aspect of Gracia's view. Just as the traditional essentialist views, Gracia's familial-historical view purports to be a universal theory of Hispanic identity that is independent of specific contexts. By contrast, Wittgenstein encouraged us to look at specific cases for specific purposes. On Wittgenstein's view, the job of the philosopher is to arrange descriptions or "perspicuous representations" (PI $\S 122$ ), that is, to provide elucidations by situating things in their historical, practical, and normative contexts. And it is of the utmost importance that these descriptions or elucidations are produced for "particular practical purposes" (PI §132). However, the philosophical standpoint adopted and encouraged by Gracia's view is not the situated perspective of an engaged critic, but the detached perspective of an observer who looks at the history of our Hispanic family sul) specie deternitatis. This lack of sensitivity to practical and normative contexts is clamaging, for it undermines 
the critical and transformative potential that a philosophical elucidation of Hispanic identity should have.

In my opinion, Gracia's familial-historical view of Hispanic identity is an important step in the right direction, but a step that could have taken us much further if it had acknowledged the practical and normative dimensions of identity. An adequate familial account of identity needs to pay closer attention to the role of agency and values in the formation of identity. Gracia's view calls attention to one of the three crucial features of cultural identity-i.e. historicity, but disregards the other two-i.e. agency and normativity. However, these features cannot be separated without distortion. As I will argue in what follows, the historicity of a cultural group or family is essentially practical and nomative.

\section{2b. Polyphonic Families: Families with Histories, Practices, and Norms.}

One of the lessons we can learn from Wittgenstein's later philosophy is that most of the concepts we use to describe ourselves and the world around us are not applied according to fixed criteria of strict identity. When we use a concept such as "game" or "chair", we treat all kinds of different things as the same although they are not strictly identical in any respect. That is, in our categorizations different things are treated as instances of the same category even though there is no feature (or set of features) that they all have in common: many different kinds of activities are called games and many different kinds of artifacts are called chairs; and we can always add new items to the list of things that fall under these concepts (we can always invent new kinds of games and produce new kinds of chairs). Wittgenstein suggested that these concepts are like families, whose members resemble one another in many different ways: some may have similar hair, others a similar nose, others may share a particular way of talking, or a similar laughter, etc. Families are composed of heterogeneous elements. There is nothing in particular that all their members must have: they simply exhibit some similarities; they share certain "family resemblances", but there is no fixed set of necessary and sufficient conditions that determine familial membership. As Wittgestein puts it, what brings together and keeps together the members of those categories that function like families is "a complicated network of similarities overlapping 
and criss-crossing." (PI §66) Wittgestein's analogy between the strength of a concept and the strength of a thread illustrates this point: "we extend our concept [...] as in spinning a thread we twist fibre on fibre. And the strength of the thread does not reside in the fact that some one fibre runs through its whole length, but in the overlapping of many fibres." (PI §67)

As I have argued elsewhere, ' the familial identity of the members of a group is crucially dependent on overlapping similarities, but it is also doubly dependent on intersecting differences: differences with members of other groups that are considered prominent, and differences among the members of the group that are considered negligible. In other words, the network of similarities in which familial identity consists must be accompanied by two distinct networks of overlapping and crisscrossing differences: one network of differences that sets apart the members of the family from the members of other families; and another network composed of those differences among the members of the family themselves that lurk in the background and are disregarded for the sake of familial identity. It is important to note that the relationship that holds between these networks is a dynamic one: differences that today set apart one family from another may become inconsequential tomorrow; and, on the other hand, internal differences that are considered negligible today may grow to be important differences tomorrow, even to the point of excluding individuals from membership in the family. At the same time, these dynamic fluctuations between the networks of differences correspond to transformations in the network of similarities that sustains familial identity, for all these networks are mutually dependent and they are shaped simultaneously. A family is a living unit whose members come and go; and, therefore, a familial identity is always subject to change and must be left open. Moreover, even when the membership in the family remains the same, the relations among the members of the family (as well as their relations with other families) change as differences become visible and family ties are relaxed. It is important to note that these networks of similarities and differences that become indicative of familial identity have a history: they result from the continued use of certain associations, that is, from treating things in a particular way in our practices. These networks of similarities and differences acquire diagnostic value simply 
because of the (criterial) significance they have been given in our practices, because they have come to be seen as symptoms of membership in a group. But those similarities and differences-as well as their diagnostic value for cultural affiliation-are always open to contestation (even if they do not face challenges and criticisms here and now); and claims about which similarities and differences can be said to be constitutive of the cultural identity of a group are always defeasible (even if not yet defeated). In my view, the networks of simi larities and differences that have become symptomatic of familial identity call for a genealogical account, that is, a genealogy of their formation through the shared ways of speaking and acting enforced by cultural practices (typically the dominant or mainstream practices within the culture).

This familial view of identity based on Wittgenstein's account of categorization makes clear that the homogeneity and fixity of cultural identities are nothing but myths. Identity should be thought of as something heterogeneous and fluid. Given the fluid heterogeneity of familial identity, it is not surprising that all attempts to reduce the shared identity of Hispanics to common properties fail. These failures have led many to conclude that we should give up Hispanic identity and retreat to national identities (Mexican identity, Cuban identity, Argentinean identity, etc.). But, as it turns out, these collective identities pose the same problems (there is no fixed set of features shared by all Mexicans, all Cubans, all Argentineans, etc). The lesson to learn here is that we should reject the essentialist assumption that a shared identity must be based on common features. The unity of Hispanics cannot be established at the expense of diversity, but on the basis of it. As Gracia puts it, the unity of Hispanics is "a unity in diversity" (p. 49); that is, it is not a unity of commonality, but a unity of community: the unity of a family. ${ }^{8}$ This is a polyphonic unity: families are intrinsically polyphonic because they contain a multiplicity of voices, standpoints, and perspectives. And the polyphony of a family is essentially dynamic: it is a living polyphony that cannot be fully controlled or tamed; in particular, it cannot be forced to conform to an exhaustive catalogue of admissible familial voices and perspectives, for what these are cannot be decided in advance, prior to the contingent historical development of the family.

My familial-historical view calls attention to the contingencies 
of the past that have contributed to the formation of our Hispanic identity; and it underscores that the future of our identity remains open and therefore presents us with a task for which we have to take responsibility. According to this view, identifying oneself as Hispanic (or as a member of any other group) is the expression of a commitment: a commitment to one's history, to a set of ongoing practices, and to a common future. What is most distinctive about cultural identity is that it involves normative attitudes that inform one's interests, values, and practices. What characterizes membership in a cultural group is a relation of normative identification, which is precisely what the metaphor of the family captures so well. Being part of a culture involves being committed to it; that is, it involves seeing oneself as part of that community or family, no matter how different its members are and how heterogeneous their practices and values can be. This is a formal commitment with no specific or fixed content. There is no list of values that we are asked to sign on to in order to become a member of the Hispanic family. But the formal commitment that is involved in the normative identification with a group creates a bond with the members of the group. This bond, which brings together the members of the group as a collectivity, is established and maintained through the commitment to a shared and coordinated agency that faces common problems and a common future-a commitment that is not affected by the fact that the members of the group will inevitably disagree about what their problems are and what their future should look like. The specific contents that our familial commitments happen to take will be determined historically through the collective agency and ongoing negotiations of the members of the group.

As Gracia saw, history produces cultural communities or families. But history is not something that simply happens to us. We make history (and remake it or reconstruct it). Of course this does not mean that we make it up. ${ }^{9}$ We don't simply invent history, but we construct it through our agency, individual and collective, conscious and unconscious. The crucial point here is that to be a member of a cultural group or family is to be committed to participate in the collective agency of the group and in the endless process of negotiation in which their values and interests get articulated and discussed. These ongoing negotiations involve a clouble dialogue: a dialogue among the members of the group 
and a dialogue of the group (and its members) with other groups (and their members). To these complex polyphonic dialogues I now turn.

\section{Tongues Untied: Polyphonic Dialogues and the Cuitural Agency of Hispanics in Particular Contexts}

The formation of a cultural identity requires an intra-cultural dialogue of an open plurality of voices (as many as possible). Through this dialogue the members of a culture can produce a multi-vocal articulation of their multiple problems, needs, values, ideals, and illusions. But this dialogue needs to be supplemented with another one that goes beyond the members of the group. For, indeed, no group - no matter how powerful or hegemonic - can fully comprehend the problems it faces and fully determine its own future independently of other groups. So an inter-cultural dialogue between the cultural group in question and other groups with which its existence is entangled is also necessary.

We need to keep cultural dialogues as open as possible, without constraining and disciplining their constitutive diversity, that is, the plurality and heterogeneity of their voices. In other words, we need to keep our dialogues polyphonic. We have to be prepared to fight homogenizing tendencies that erase differences as well as normalizing tendencies that make certain articulations of identity mainstream and relegate other identity formations to the margins. We must resist the vain and dangerous attempt to tame the indomitable polyphony of intra- and inter-cultural dialogues. Coercive social and cultural forces and institutions (from school to the family and the media) are responsible for the homogenization of mainstream identities and the marginalization of those identities that don't conform to social expectations and established social norms. These coercive forces-which can come from inside one's own group or community as well as from other social units-limit the self-expression of individuals and groups as they navigate through intra-cultural and inter-cultural dialogues. They often restrict, handicap, and even preclude the emergence and development of alternative identities that can be subversive and transformative, for they weave the networks of similarities and differences that support relations of identification in new and alternative ways. A crucial part of this social and cultural process of disciplining identities and taming their polyphony 
is the attempt to subdue and domesticate new languages and dialects that people develop to express their experiences, ideals, values, needs, interests, etc. These new linguistic formations (new language-games) can facilitate the rearticulation or reconstruction of established groups or families and the creation of new ones. Therefore, keeping cultural dialogues open and guaranteeing the flourishing of polyphonic identities requires resisting the taming of one's tongue.

Of special interest in this respect are the frontier identities and border languages that trouble cultural dialogues by underscoring their indomitable diversity and the complex dialectic between intra-familial and inter-familial relations. These are the languages and identities of those who live at the limits or borders between communities - en la frontera-and often have multiple familial affiliations, belonging to different cultural groups or families simultaneously. ${ }^{10}$ Frontier identities and border languages have recently received special attention in the literature, especially in the pioneer work of Gloria Anzaldúa. In Borderlands/La Frontera Anzaldúa tells us that at the core of her Chicana identity is a cultural duplicity that makes her a stranger even to the members of her own family, let alone to those of other families, to whom she appears as fully foreign and even deviant. Those who have frontier identities often display signs of cultural otherness in their faces and bodies, in their manners and comportment, and in their speech. These are signs that often come under attack, being subject to the domesticating social and cultural forces that conspire to erase them. Our bodies and habits are disciplined; our tongues are tamed. In this respect, Anzaldúa talks about the concerted efforts "to get rid of our accents", which she describes as a violent attack on one's identity and basic rights: "Attacks on one's form of expression with the intent to censor are a violation of the First Amendment. El Anglo con cara de inocente nos arrancó la lengua. Wild tongues can't be tamed, they can only be cut out." (p. 76)

It is important to note that the efforts to tame one's tongue do not come only from outside one's group or family. Anzaldúa poignantly remarks that her Chicana tongue is not only tamed -and ultimately "cut out"-by the Anglos, but also by other Hispanics. Chicano Spanish is not recognized and respected by many other Spanish speakers: "Even our own people, other Spanish speakers, nos quieren poner candados en la boca. [...] 
Chicano Spanish is considered by the purist and by most Latinos deficient, a mutilation of Spanish." (pp. 76-77) And this scorn and disciplining efforts come not just from other Spanish speakers, but from Chicanas and Chicanos themselves, who have internalized the alleged inferiority of their language and, ultimately, of their identity. "Chicanas who grew up speaking Chicano Spanish have internalized the belief that we speak poor Spanish [...] we use our language differences against each other." (p. 80) Thus Chicanos are left speaking "an orphan tongue":

Deslenguadas. Somos las del español deficiente. We are your linguistic nightmare, your linguistic aberration, your linguistic mestisaje, the subject of your burla. Because we speak with tongues of fire we are culturally crucified. Racially, culturally, and linguistically somos huérfanos-we speak an orphan tongue. (Anzaldúa 1999 , p. 80)

The domestication of a border language such as Chicano Spanish leaves its speakers tongue-tied, speechless, indeed as if their tongues had been cut out, for they are rendered unable to express themselves in their own ways. The social stigmatization and cultural orphanage of their forms of expression amount to the marginalization of their very identities: ${ }^{11}$ "If a person, Chicana or Latina, has a low estimation of my native tongue, she has also a low estimation of me. [...] I am my language. Until I can take pride in my language, I cannot take pride in myself." (pp. 80-81) This moment of self-empowerment through one's tongue is a moment of cultural pride and cultural affirmation. It involves a demand for cultural solidarity, for the formation of a proud linguistic community liberated from self-hatred, a community in which the marginalized tongue finds a home and a family and is no longer orphan. Anzaldúa makes this point in very Wittgensteinian terms, calling for the construction of a "We" —un "Nosotras"—around a common tongue that corresponds to a shared form of life. She writes: "Chicano Spanish is a border tongue which developed naturally. [...] Un language que corresponde a un modo de vivir. Chicano Spanish is not incorrect, it is a living language. [...] for a people who cannot entirely identify with either standard (formal, Castillian) Spanish nor standard English, what recourse is left to them but to create their own language? A language which they can connect their identity to, one capable of communicating the 
realities and values true to themselves." (p. 77)

As Anzaldúa suggests, a common tongue that can express people's "realities and values" makes possible the cultural process of community formation around a shared form of life. Through a common tongue people can articulate their shared experiences, problems, needs, interests, values, etc.; and thus cultural solidarity becomes possible. For this reason, Chicano Spanish deserves recognition and respect from the members of the Hispanic family as well from other cultural groups. For this reason also, we ought to acknowledge the special cultural productivity of border tongues in general, for they make possible the articulation of new experiences and new forms of identity, facilitating the diversification of cultural norms and cultural expectations. The task of cultural self-affirmation through language is a complex and always ongoing task. It is extremely complex because it has to be constantly diversified, making sure that no voices are left out. ${ }^{12}$ And it is also a never-ending task, for cultures and cultural identities are living things that are always changing.

Keeping tongues untied is a pressing task for which we are all collectively responsible, as individuals and as communities. But it is indeed not an easy task. In and through cultural dialogues we need to secure recognition and respect for all but especially for those who have been silenced and may be left without a voice, those whose experiences depart from normalized cultural expectations, those whose identities do not fit into the established cultural molds available to them. There are cultural identities that need a new language to express themselves and the creation of a supportive community in which to flourish, identities thatwithout special attention and care-are doomed to isolation and silence because they will remain marginalized and tongue-tied. Keeping tongues untied, keeping cultural dialogues polyphonic, involves a process of constant interrogation and challenge, a process of radical but immanent critique of our cultural practices and the ways in which they include and exclude people through the sedimentation of cultural similarities and differences. We need to destabilize whatever cultural borders or frontiers are erected, whatever relations of inclusion and exclusion are established in the cultural landscape. This critical activity of interrogation and destabilization of cultural boundaries is epitomized in the work of the Tijuana-based Chicano performance artist Guillermo Gomez- 
Peña. He aptly describes his performance art as "dangerous broder-crossing" (2000) and as an exercise in "the semiotics of the frontier" and "the epistemology of multiplicity" (2002). In his performances Gomez-Peña parodies the attitudes towards cultural differences that contribute to perpetuate oppression and marginalization. In his recent work (2002) he develops a performative critique of the objectivism of academic discourses that treat cultural differences as mere objects of study. He turns the tables on scientific observers, parodically mimicking their objetivizing gaze, when he acts as "un antropo/oco fronterizo" who crosses the borders in search for differences to add to the catalogue of exotic behavior. In his performative rendering of reverse anthropology, the "antropo/oco" Gomez-Peña captures specimens of gringos who are displayed in cages, as trophies of his cultural expedition, to an audience that is asked to form a We-a community - whose identity is defined in opposition to these cultural others.

Gomez-Peña's parodic performances also contain a performative critique of the cultural exoticism that transforms cultural differences into products of consumption. This consumerist attitude toward differences is patent in cultural tourism. In their cultural explorations tourists make a spectacle of cultural differences ("the spectacularization of the bizarre"); and the more distant the cultural differences encountered, the bigger the thrill and the more reassured the tourists will feel about their own ways upon return from their trip. This cultural exoticism also trivializes otherness through the commodification of cultural differences that can be found in fashion and pop culture: "the young hipsters of the 90 s have selectively borrowed elements from numerous third world 'pet cultures', to create their own designer tribalism." (2000, p. 272) This cultural consumerism results in the normalization of cultural differences and the creation of "alternative mainstreams". As Gomez-Peña puts it, the legacy of the 1990s is "that the insatiable and undifferentiated mass of the so-called 'mainstream' has finally devoured all margins, and the more dangerous, 'other', and exotic these margins, the better. In fact, stricto sensu, we can say that there are no margins left. 'Alternative' thought, fringe subcultures, and so-called radical behavior have actually become THE mainstream." (Ibid.)

Our challenge in the 21 st century is to recognize and respect 
cultural differences without exoticizing them or commodifying them, without contributing to their marginalization or assimilating them to the mainstream. This challenge calls for the troubling of the relation between center and periphery, for the interrogation of the boundaries that separate cultural centers from cultural margins. Gomez-Peña's performances often involve a subversive violation of cultural expectations that invites the critical questioning and problematization of cultural boundaries. But it is important to note that we don't need physical and geographical borders to engage in the transgression of cultural boundaries and social norms. Cultural boundaries and the differences and exclusions they institute exist even when there are no visible frontiers. And the critical interrogation of these boundaries should not be left only to performance artists and "professionals" of cultural otherness such as Gomez-Peña. All of us, in our own everyday activities and performances as cultural agents, should contribute to the critical questioning, reconstruction, and rearticulation of cultural boundaries. Creative and reconstructive "border-crossing" can take place within any given community and cultural landscape, even at what is considered the very core or center of the familial group in question and its "homeland" or native cultural space. This productive "border-crossing" can take place even if the physical and geographical borders are not within sight, for indeed there are more frontiers than the visible ones-there are borders, very real borders (even if they are not physical and visible) whenever there are relations of inclusion and exclusion.

An example of cultural "border-crossing" that takes place far from (and independently of) physical borders can be found in the unorthodox religious practices of marginalized groups in the urban ghettos of Mexico City. These include the practices of worshiping Santa Muerte, a religious icon that "looks like hell: a scythe-wielding skeleton with a blood-curdling grin" (as reported by The New York Times, March 26, 2004, A4). This vision of hell attracts those who come from places that feel like hell on earth, inner-city neighborhoods such as Tepito, a crime-ravaged slum in the heart of Mexico City. Santa Muerte is "an angel of last resort for outlaws and outcasts" (Ibid.). Her followers are people who live on the fringes of society, people who have been abandoned by their government and disparaged by their church: prostitutes, petty thieves, smugglers, drug dealers and addicts, and criminals 
of all sorts, who have been excluded from mainstream culture and its practices, where their participation is deemed inadmissible because of the way they speak, the way they dress, their manners and habits, and indeed their lifestyle. They know they cannot go to La Virgen de Cuadalupe dressed like that, speaking like that, living like that. And therefore they take their prayers and candleofferings elsewhere, to Santa Muerte. Her worshipers say that they adore Santa Muerte because she is their own creation and she is like them: she is depicted as enjoying chocolates and jewelry, cigarettes and whiskey. Santa Muerte has been created by the people in their own image. This is where Santa Muerte's strong popular appeal among Mexico's impoverished and neglected masses lies. This religious icon has been constructed and is used as a site of cultural identification that fills a void created by social and cultural exclusions. As Hayde Solís Cárdenas-a street vendor who sells smuggled sneakers in Tepito-is reported to have said, La Virgen de Cuadalupe "would not sympathize with a life like hers, tending rather to well-off people with college degrees and nice clothes", but Santa Muerte "hears prayers from dark places" since "she was sent to rescue the lost, society's rejects" (Ibid.).

The Catholic Church in Mexico has condemned Santa Muerte services as devil worship, and law enforcement authorities keep a close eye on this cult, which they link to street violence and delinquency. But this tout court condemnation and persecution are problematic and socially irresponsible, for they simply ignore that these cultural practices fulfill a crucial social need for cultural affirmation and collective self-expression. And the rejection of new forms of cultural expression is especially worrisome when it is issued from privileged places of power, and when it targets the cultural agency and voices of people who have been left out of accepted practices and institutions. It is too bad that marginalized cultural practices such as those surrounding Santa Muerte are rejected off hand by the mainstream, although this is certainly not surprising, since the authorities and institutions of mainstream culture have something at stake here, namely, retaining their privileged and hegemonic status by maintaining the established boundaries between acceptable and inadmissible forms of cultural expression. Of course, my claim is not that the unorthodox religious practices surrounding Santa Muerte will surely be the path to human flourishing for the oppressed and 
marginalized groups that participate in them. They may or may not be. But my point is simply that we must allow for alternative cultural practices like these to articulate people's experiences and to give cultural expression to their interests, values, aspirations, fears, goals, ideals, and illusions. ${ }^{13}$

My polyphonic view contends that our cultural practices should be open to all possible voices. Now, it is important to note that this notion of cultural openness welcomes all voices but not all forms of symbolic interactions. For, indeed, there are non-dialogical ways in which voices can interact with other voices so as to oppress them, to marginalize them, and even to silence them or destroy them altogether. Polyphonic dialogues can only contribute to cultural openness if, without excluding any voice (or set of voices) in particular, they do everything they can to avoid symbolic impositions, marginalizations, and forms of silencing (such as, for example, hate speech). It is not at all clear that the best way to avert these dangers of symbolic oppression is prohibition. In this sense, in Excitable Speech (1997) Judith Butler has argued quite convincingly that censorship is not the best way of dealing with the symbolic disempowerment and silencing that result from hate speech; and there are indeed good reasons to believe that speech codes that simply prohibit the use of certain terms are not particularly effective in the fight against symbolic oppression. Cultural openness is not secured by legal mandates and prohibitions. Securing cultural openness must involve arranging our symbolic practices (and the discursive contexts in which they take place) in such a way that any attempt to disempower or silence voices is discouraged and neutralized, making it very difficult (perhaps even impossible) for such attempts to succeed. But it would be naive to think that we can create discursive practices and spaces that eliminate all possible forms of exclusion and silencing. It would also be wrong to assume that the task is simply to identify those voices that are exclusionary and antidemocratic (the silencing voices of racists, sexists, homophobes, etc), because voices are plastic and dynamic: ${ }^{14}$ insofar as they are alive, they can change and are therefore moving targets that don't admit reification (they can be cooperative and inclusive here and now, and yet antagonistic and exclusionary there and then).

We need to allow for alternative cultural spaces and 
alternative cultural practices. We have to make it possible for people to develop their own ways of expressing themselves and of articulating their experiences, problems, interests, etc. We have the individual and collective responsibility to do everything we can to keep cultural dialogues open and to allow for the identities of groups and individuals to be polyphonic, that is, to contain a (diverse and heterogeneous) plurality of voices. We have to keep tongues untied. We have to make our cultural dialogues polyphonic. Of course, open and polyphonic dialogues do not guarantee cultural solidarity, social justice, the mitigation of oppression, and the flourishing of happier cultural groups or families. The achievement of these goals is never guaranteed. But what untying tongues and having polyphonic dialogues can do is to increase the capacity that groups and individuals have to negotiate their pasts, presents, and futures, freely, so that the contingent achievement of cultural solidarity, social justice, liberation, and happiness can come to depend (at least to some degree) on their own agency.

When tongues are untied, we do not know what they will say, or even in what language they will speak; but we know at least this: that they will be able to talk. "I will have my voice [...]. I will have my serpent's tongue-my woman's voice, my sexual voice, my poet's voice. I will overcome the tradition of silence." (Anzaldua 1999, p. 81)

\section{Notes}

'See Bakhtin (1981).

${ }^{2}$ I have clone this in my (2004). For a fuller discussion of this issue as it emerges in the discussion of Hispanic/Latina identity, see Alcoff (2000).

${ }^{3}$ For example, in Post-ethnic America David Hollinger (2000) argues for the construction of an American identity without ethnic or racial meanings. I have argued against the post-ethnic view at length in my (2004). See also Alcoff (2004).

${ }^{4}$ Arguments for the idea that cultural identity is always and necessarily bound up with internal differences can be found in Benhabib (2002) and Narayan (1997). Drawing on the writings of José Martí, I have also developed a heterogeneous and pluralistic view of cultural identity through the notion of "unity through diversity". See my (2004). 
${ }^{5}$ For a full analysis and discussion of this notion, see Muñoz (1999) and my (2003).

${ }^{6}$ See, for example, Alcoff and Mendieta (2000) and Schutte (1993).

7 See Medina (2003).

${ }^{8}$ In order to properly understand my familial account of identity, two caveats are in order. First, in my view, the notion of a family should not be understood as a purely biological concept, but rather, as a hybrid notion that contains social and political elements as well as biological ones. Families are not just biological groups, but social structures and legal institutions. Secondly, we have to keep in mind that there are all kinds of family and, therefore, only a pluralistic notion of "family" can be useful for the analysis of collective identities. My Wittgensteinian approach does not rely on the patriarchal and heterosexist familial model that has been dominant in the West. Far from being complacent with this model, the genealogical approach behind my familial view is intended to subvert it. In this sense, my familial view connects with ongoing efforts in the literature on identity (esp. in feminist theory and queer studies) to rearticulate the very notion of a family and to subvert what is typically understood by "family values". See my (2003).

${ }^{9}$ For a balanced discussion of the complex relations between the objective and the intersubjective aspects of history, see Alcoff (2004).

${ }^{10}$ As I have argued in my (2003), all of us have multiple familial identities, with intersecting family ties that are often in tension. As GomezPeña (2000) puts it, "we are all members of multiple communities, at different times and for different reasons. Most communities in the $90 \mathrm{~s}$ are fragmented, ephemeral, dysfunctional, and insufficient. They can only contain and 'include' selected aspects of ourselves." (p. 277)

${ }^{11}$ This silencing is certainly gender-specific. As Anzaldúa notes, in the case of Chicanas, the silencing of their ethnic voices converges with the silencing of their female voices. In this sense she describes how she was raised, as a woman, in a "tradition of silence": "Ser habladora was to be a gossip and a liar, to talk too much. [...] Hocicona, repelona, chismosa [...] are all signs of being mal criada. In my culture they are all words that are derogatory if applied to women-l've never heard them applied to men." (p. 76) This double oppression and marginalization as woman and Chicana that Anzaldúa describes reminds us that there are multiple and converging fronts of oppression. The phenomenon of multiple oppression has been discussed and theorized by Lugones (2003). It is also 


\section{Ethnlc Studles Revlew Volume 29}

the topic of my (2003).

${ }^{12}$ As Anzalclúa points out, "there is no one Chicano language just as there is no one Chicano experience." (p. 80) Even for a single inclividual, taking pricle in one's tongue is typically not a single, unified task, but a plurality of tasks, with multiple fronts, for we speak in many tongues: "because we are a complex, heterogeneous people, we speak many languages." (p. 77)

${ }^{13}$ In this respect some trends within liberation theology have done very important work in gaining recognition and respect for the unorthodox religious practices of oppressed classes and marginalized groups. See especially Althaus-Reid (2000).

${ }^{14}$ For a full discussion of the plasticity of voices and their agency, see chapters 3 and 4 of my new book (2006). Chapter 5 elaborates the claims I have made in this paragraph through a critical examination of symbolic processes of silencing and exclusion.

\section{References}

Alcoff, L. (2000): "Is Latina/o a Racial Identity?", in J. Gracia and P. De Greiff (Eds.), Hispanics/Latinos in the United Status. Ethnicity, Race, and Rights, (New York and London: Routledge), pp. 23-44.

Alcoff, L. (2004): "Against 'Post-Ethnic' Futures", Journal of Speculative Philosophy 18, pp. 99-12

Alcoff, L., and Mendieta, E., Eds. (2000): Thinking from the Underside of History. 2nd Edition (New York: Rowman \& Littlefield)

Althaus-Reid, M. (2000): Indecent Theology (New York and London: Routledge)

Anzalclúa, G. (1999): Borderlands/La Frontera: The New Mestiza. 2nd Edition (San Franscisco: Aunt Lute Books)

Bakhtin, M. M. (1981): The Dialogic Imagination (Austin: University of Texas Press)

Benhabib, S. (2002): The Claims of Culture (Princeton and Oxford: Princeton University Press)

Butler, J. (1997): Excitable Speech: A Politics of the Performative (New York and London: Routledge) 
Gomez-Peña, G. (2000): Dangerous Border-Crossers (New York: Routledge)

Gomez-Peña, G. (2002): El MEXterminator. Antropología Inversa de un Performancero Post-Mexicano (Mexico City: Editorial Océano)

Gracia, J. (2000): Hispanic/Latino Identity (Oxford: Blackwell)

Hollinger, D. (2000): Post-ethnic America (New York: Basic Books)

Lugones, M. (2003): Pilgrimages/Peregrinajes: Theorizing Coalition against Multiple Oppression (New York: Rowan and Littlefield)

Medina, J. (2003): "Identity Trouble: Disidentification and the Problem of Difference", Philosophy and Social Criticism 29 (6), pp. 657-82.

Medina, J. (2004): "Pragmatism and Ethnicity: Critique, Reconstruction, and the New Hispanic", Metaphilosophy 35 (1/2), pp. 115-46.

Medina, J. (2006): Speaking from Elsewhere: A New Contextualist Perspective on Meaning, Identity, and Discursive Agency (Albany, NY: SUNY Press)

Muñoz, J. E. (1999): Disidentifications. Queers of Color and the Performance of Politics (Minneapolis: University of Minnesota Press)

Narayan, U. (1997): Dislocating Cultures: Identities, Traditions, and Third-World Feminism (New York and London: Routledge)

Schutte, O. (1993): Cultural Identity and Social Liberation in Latin American Thought (Albany: SUNY Press)

Wittgenstein, L. (1976): Philosophical Investigations (Oxford: Blackwell) 